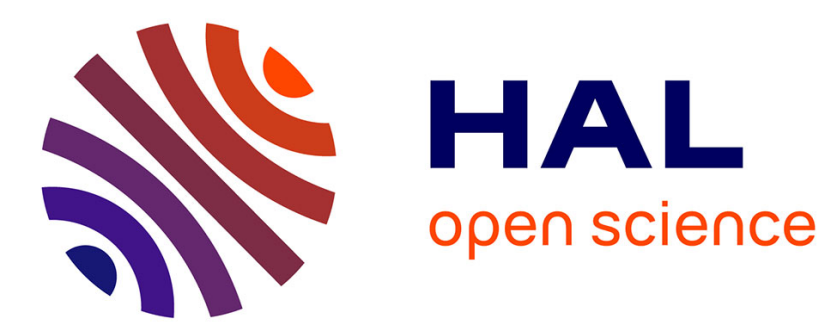

\title{
Is the Insurance Cost-of-Capital Fair?
}

\author{
Mathieu Gatumel
}

\section{To cite this version:}

Mathieu Gatumel. Is the Insurance Cost-of-Capital Fair?. 2011. halshs-00658729

\section{HAL Id: halshs-00658729 \\ https://shs.hal.science/halshs-00658729}

Submitted on 11 Jan 2012

HAL is a multi-disciplinary open access archive for the deposit and dissemination of scientific research documents, whether they are published or not. The documents may come from teaching and research institutions in France or abroad, or from public or private research centers.
L'archive ouverte pluridisciplinaire HAL, est destinée au dépôt et à la diffusion de documents scientifiques de niveau recherche, publiés ou non, émanant des établissements d'enseignement et de recherche français ou étrangers, des laboratoires publics ou privés. 


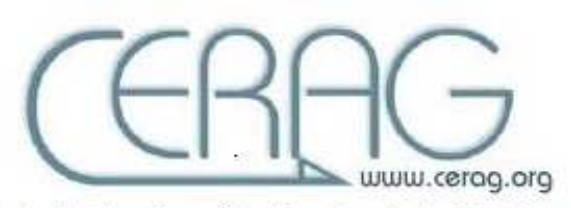

Centre d'Etudes et de Recherches Appliquées d̀ la Gestion_U.M.R. C.N.R.S. 5820

\title{
CAHIER DE RECHERCHE $n^{\circ}$ 2011-07 E2
}

\section{Is the Insurance Cost-of-Capital Fair?}

\author{
Mathieu Gatumel
}




\title{
Is the Insurance Cost-of-Capital Fair?
}

\author{
Mathieu Gatumel ${ }^{*}$ \\ University of Grenoble, IUT2-CERAG
}

February 13, 2011

\begin{abstract}
This paper aims at presenting the insurance cost-of-capital computation issue. It highlights two methodologies introduced by Chief Risk Officer Forum (2008) to perform the cost-of-capital rate and which more or less justify the risk premium adopted by supervisory authorities. These strategies are based either on market return of insurance companies or on the modelling of insurance business profit and loss. We estimate a cost-of-capital rate corresponding to these basic methodologies and point out benefits and drawbacks of each method. We show that the risk premium adopted by the supervisory authorities is inside the interval confidence given either by market data or by the modelling : thus it would correspond to a fair cost-of-capital rate. In addition to that we discuss the fact that this rate is quite low and allow to adopt a relative conservative strategy.
\end{abstract}

Keywords:

JEL classification:

* University of Grenoble, IUT2-CERAG, Place Doyen Gosse, 38031 Grenoble, France. Email: mathieu.gatumel@iut2.upmf-grenoble.fr. Tel.: +33.4.76.28.45.78. 


\section{Introduction}

For ten years, the European Commission, actuarial associations and supervisory authorities focused on improving the efficiency and effectiveness of the oversight of insurance entities. In parallel, discussions in the field of financial accounting have developped an explicit framework, one of the main component being the valuation of the financial securities to their fair value. In order to improve shareholder information, willingness to give a major rule to market prices seems to be obvious because they are considered as information vector. Fair value refers to values that are consistent with those observed in deep and liquid financial markets. It is the price at which assets or liabilities may be traded between well-informed players. In other words, the reference of fair value is the market value. It follows that assets and liabilities have to be characterized by market value - they have to be transferable in a secondary market - or that market value may be estimated. In such a framework, noarbitrage and risk-neutral probability allow to determine fair value.

It would be possible to consider that asset prices correspond to the expected value of future payoffs, the expected value being computed through the "objective" probability. The probability is called "objective" it refers to the object, the risk itself and not its perception. "Objective" probability may be estimated through the "historical" probability, assessed with some mathematical or statistical models. Such an approach characterized for instance the property and casualty insurance industry. In this case, the result takes also into account a loading factor determinated for example with an implicit utility.

In the financial world, however, the pricing of complex products is not based on an "objective" probability but on an "implicit" probability because of the consequences of the perfect markets and in particular of the notion of noarbitrage. Thus, the fair value of a financial asset is given by the expected value of the discounted payoffs computed through a "new" probability. Called risk-neutral probability, $Q$, it is changing the initial and objective probability in order to reinforce the weight of unfavourable events in a risk adverse environment. In financial economics, it allows to capture the price of risk. The theory highlights that in nice cases (Embrechts (2000)), $Q$ is the unique probability for which the best estimate of the future value of an asset is its present value, with the available information. In other words, that means that in nice cases it is possible to have one and only one price of risk.

What are the nice cases? Following Black and Scholes (1973) or Merton (1973), nice cases allowing a unique risk neutral probability are cases where the markets are complete. Any contingent claim can be attained through a selffinancing trading strategy. More precisely, if markets are such that there are sufficiently many basic assets so that new assets can be represented as linear combinations - called relication strategy - of these basic assets and that these basic assets have a unique price, then markets are complete. When a claim cannot be represented from a replicating portfolio, the market is incomplete. 
In such a market, without fully information on investor preferences, only a price interval can be computed. Financial litterature have developped a lot of tools which aim at evaluating the price of contingent claims in the case of incompte markets (see Mø ller (2002) for a review). The main idea is that the price of the contingent claim is inside a price interval arbitrage-free. Then, the goal consists in the reduction of the price interval.

Nevertheless, traditional methods used in finance in the case of incomplete markets assume that the market is slightly-incomplete. In such a case, there are fewer missing assets than available assets. However, it is not always possible to find a replicating portfolio built from available assets which replicate all expected liabilities. It is for instance possible in the case of death-financial assets linked products. Mortality risk is reduced through the law of large numbers and thus the potential consequences of an epidemic become negligible. But, in some cases, it is not possible to replicate the flows, excepted with prohibitive strategies. Thus, flows issued of long-tail lines of business may have an horizon above the available fixed-return assets. Similarly, the catastrophe risks can only be imperfectly replicated in the financial markets, despite the development of insurance linked securities. The absence of potential replication may be a major issue in property and casualty $(P \& C)$ insurance for the event risk: windstorm, earthquake, flood, terrorism but also emergent risk, legal changes, etc. If the law of large number seems to be respected in $\mathrm{P} \& \mathrm{C}$ insurance, some dependencies between individual risks reinforce the tails of the insurance risk distributions, causing a systematic risk of insurance risk.

In addition to that, another limitation to the replicating portfolio as valuation tool for $\mathrm{P} \& \mathrm{C}$ insurance risk is the inadaptation of a reasoning limited to the systematic risk. If financial theory highlights that shareholders are able to eliminate the idiosyncratic risk, some works have suggested that this risk has a cost which constraints companies to manage their risks as a whole - systematic and idiosyncratic - even after having integrated the benefits of the diversification. Vaughn (1999) provides justifications of this argument. The limitations of the theoritical no-arbitrage model and of the replicating portfolios are called frictional costs. These costs do not modify the traditional financial paradigm but aim at reducing the mistakes that it could generate. If they characterize also the life insurance business, the frictional costs are certainly more important in $\mathrm{P} \& \mathrm{C}$ insurance and their valuation is more difficult in this case. One of the main reason is the difficulty for a third party to know the risk taken by an insurance company, risk which may reduce the market value of the firm, because of the cost due to the information asymmetry.

To solve practically these issues, the Draft Solvency II Directive suggests in article 75 that the valuation of technical provisions (for non hedgeable risks) shall be the sum of a best estimate and a market value margin. In order to determine it, a cost-of-capital methodology should be used. It bases the risk 
margin on the theoritical cost to third party to supply capital to the company in order to protect against risks to which it could be exposed. Under the Costof-Capital approach, the market value margin is determinated by capturing the cost of providing an amount of eligible own fund equal to the solvency capital requirement (SCR) necessary to support insurance obligations over their life time. In other words, under a cost of capital approach, the market value margin is calculated as the present value of the cost of holding the solvency capital requirement for non-hedgeable risks during the whole run-off period of the in-force portoflio. Thus, one needs to estimate both the solvency capital requirement related to non-hedgeable risk and the annual cost of capital rate. The cost of capital in each year would be given by the product of the solvency capital requirement of each year and the underlying cost of capital rate. The market value margin is then obtained by discounting these amounts:

$$
\operatorname{MVM}=\operatorname{CoC} \times{ }_{t=1}^{\mathrm{X}^{\mathrm{T}}} \frac{\mathrm{SCR}_{\mathrm{t}}}{\left(1+\mathbf{r}_{\mathrm{t}}\right)^{\mathrm{t}}},
$$

where $r_{t}$ stands for the risk-free rate at date $t$ and $T$ corresponds to the time horizon of the in force technical provisions.

According to European Commission (2007), European Insurance and Reinsurance Federation (2008), and Chief Risk Officer Forum (2008), a single cost-ofcapital rate shall be used by all insurance undertakings and for all lines of business. QIS 5 Technical Specifications stand that all participants should assume that this cost-of-capital rate is 6\% (above the relevant risk-free interest rate), following the figure of the Swiss Solvency Test (see for example European Insurance and Reinsurance Federation (2008)).

This paper aims at highlighting two methodologies presented by Chief Risk Officer Forum (2008) to perform the cost-of-capital rate and which justify a return equal to $6 \%$. These strategies are based either on market return of insurance companies or on the modelling of insurance business profit and loss. We estimate a cost-of-capital rate corresponding to these basic methodologies and point out benefits and drawbacks of each method. We show that the risk premium adopted by European Insurance and Reinsurance Federation (2008) is inside the interval confidence given either by market data or by the modelling : thus $6 \%$ would correspond to a fair cost-of-capital rate. In addition to that we discuss the fact that this rate is quite low and allow to adopt a relative conservative strategy.

This paper is organized as follows. Section 2 presents methodologies used by Chief Risk Officer Forum (2008). Section 3 presents our datasets. Section 4 provides some basic results. Section 5 discusses on the models and suggests some improvements. Section 6 concludes. 


\section{Methodologies}

\subsection{Using market data}

The Capital Asset Pricing Model and the Fama-French two factors models are methodologies used by Chief Risk Officer Forum (2008) to provide some estimators for the equity risk premium. The CAPM of Sharpe and Linter, the most popular model to estimate the cost of equity of publicly traded companies, expresses the cost of capital rate as the sum of the risk-free rate and a market risk premium based upon the systematic risk. The Fama-French two factors model has been developped in order to improve the explanation power of the model by adding a second factor to the model. This factor is the ratio of the book value of equity to the market value of equity (BV/MV ratio). This ratio reflects the financial distress. The financially vulnerable firms have higher values of this ratio than stronger fims. This factor controls for the tendency of investors to require higher expected returns on stocks in financially vulnerable firms since these firms will perform particularly poorly exactly when individual investors' portfolio are experiencing overall losses.

In order to determine a pure cost of capital rate for life and non-life insurance, and to take into account the fact that most of the companies participate in both industries, it is necessary to reflect the relative proportion of their entire portfolio of businesses. Accordingly, Cummins and Phillips (2005) (after Ehrhardt and Weiss (1992) and Kaplan and Peterson (1998)) use the fullinformation industry beta - FIIB - which allows to decompose the individual company cost estimates into industry specific cost estimates. The underlying insight is that the observable beta for the overall firm is a weighted average of the unobservable betas of the underlying lines of business.

In other words, following the CAPM the cost of capital rate is as follows:

$$
r_{i t}-r_{f t}=\alpha_{i}+\beta_{i} \times\left(r_{m t}-r_{f t}\right)+e_{i t},
$$

whereas for the FF2F model it can be expressed as:

$$
\mathbf{r}_{\mathrm{it}}-\mathbf{r}_{\mathrm{ft}}=\alpha_{\mathrm{i}}+\beta_{\mathrm{mi}} \times\left(\mathrm{r}_{\mathrm{mt}}-\mathbf{r}_{\mathrm{ft}}\right)+\beta_{\mathrm{vi}} \times \pi_{\mathrm{vi}}+\eta_{\mathrm{it}},
$$

where $r_{i t}$ is the monthly return on the stock of the firm $i$ in month $t, r_{f t}$ is the corresponding risk-free rate, $\mathbf{r}_{\mathrm{mt}}$ is the monthly return on the value-weighted market portfolio, $\pi_{\mathrm{vt}}$ is the additional factor included to capture financial distress, $\beta_{\mathrm{i}}$ is the estimated CAPM beta, $\beta_{\mathrm{mt}}$ and $\beta_{\mathrm{vt}}$ are the estimated market and value risk coefficients, $e_{i t}$ and $\eta_{i t}$ are the error terms.

In the case of the CAPM, the FIIB regression estimated is:

$$
\beta_{i}={ }_{j=1}^{X} \beta_{f j} \omega_{i j}+\xi_{i},
$$


with $\beta_{\mathrm{i}}=$ firm i's overall CAPM market systematic risk beta coefficient, $\beta_{\mathrm{fj}}=$ the full-information CAPM market systematic risk beta for industry $\mathbf{j}, \omega_{\mathrm{ij}}=$ firm i's industry participation weight for industry $\mathrm{j}$, and $\xi_{\mathrm{i}}=$ random error term for firm $i$.

In the case of the $\mathrm{FF} 2 \mathrm{~F}$ systematic risk factor, the FIIB regression is exactly the same: $\beta_{\mathrm{m}} \mathrm{i}={ }_{\mathbf{j}=1} \beta_{\mathrm{fmj}} \omega_{\mathrm{ij}}+v_{\mathrm{i}}$. Cummins and Phillips (2005) show that the relevant FIIB regression for the $\mathrm{BV}$-to-MV beta is:

$$
\beta_{v i}={ }_{j=1}^{X} \beta_{f 1 v j} \omega_{i j}+\beta_{f 2 v} \ln \frac{B V_{i}}{M V_{i}},
$$

with $\beta_{\mathrm{v}} \mathrm{i}=\mathrm{BV}$-to-MV beta estimate firm $\mathrm{i}, \beta_{\mathrm{f} 1 \mathrm{vj}}=$ the full-information BV-toMV beta intercept coefficient for industry $\mathbf{j}, \beta_{\mathrm{f} 2 \mathrm{v}}=$ the full-information BVto-MV beta slope coefficient, $\omega_{\mathrm{ij}}=$ firm i's industry participation weight for industry $\mathrm{j}_{\mathrm{j}}$ and ${ }_{\mathrm{i}}=$ random error term for firm $\mathrm{i}$.

\subsection{Using modelling strenghts}

Another method to compute the cost of capital rate is based on the frictional cost approach. Following Hancock et al. (2001), the frictional capital costs represent the insurer's cost of taking insurance risk and capture the opportunity costs shareholders incur when investing capital via an insurance company rather than directly in the financial markets. The double taxation costs, the financial distress costs, the agency costs and the costs of regulatory restrictions are the sources of the frictional costs. The double taxation costs correspond to the costS due to the fact that shareholder's profit are taxed both as benefit and as dividend. Financial distress costs are costs which arise when an insurer have to subscribe additional capital to meet its financial obligations. Agency costs are due to the lack of transparency and informational asymmetry between the management and the shareholders. In particular, shareholders may have some difficulties to know the level of risk retained by the company and thus ask for an additional risk premium. Lastly, the costs of the regulatory restrictions are due to the constraints imposed by the regulator in terms of asset allocation and capital management.

Chief Risk Officer Forum (2008) assumes that the agency and regulatory restriction costs have not to be modelled. The CRO Forum believes this is appropriate due to the level of supervisor scrutiny likely under Solvency II and because any residual agency costs are less likely to be related to non-hedgeable risk on the in-force business and are more likely to be associated with management efforts to grow the franchise.

Thus, the cost of capital appears to be the sum of the double taxation costs and of the financial distress costs: $\mathrm{CoC}_{\mathrm{DT}}$ and $\mathrm{CoC}_{\mathrm{FD}}$. 
Let $\alpha$ be the confidence interval at which the firm is capitalized, EC $(\alpha)$ the actual capital of the firm and $\mathrm{CoC}(\mathrm{EC}(\alpha))$ the cost of capital rate. In order to model it, the following assumptions are done:

- $\quad$ the P\&L is normally distributed, with mean EC $(\alpha) \times \operatorname{Rf}$ and volatility $\sigma$, where $\mathbf{R}_{\mathrm{f}}$ is the risk-free rate;

- $\quad$ we denote by $\mathrm{x}$ the annual result of the firm;

- $\quad \tau$ is the corporate tax rate;

- $\quad \mathrm{T}_{\operatorname{tax}}$ is the tax carry forward period in years.

The double taxation costs are the following:

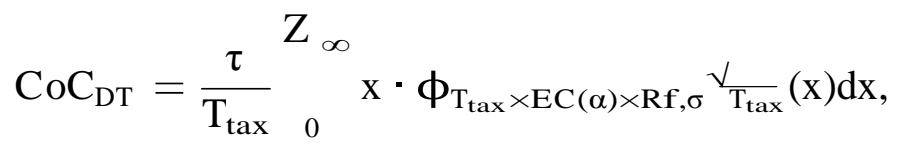

Following the assumption that if the firm's equity drops below the SCR, the company needs to obtain new capital, the financial distress costs may be expressed by:

$$
\mathrm{CoC}_{\mathrm{FD}}=\mathrm{Z}_{-\infty}^{\mathrm{Z}_{0}}(\mathrm{SCR}-\mathrm{x}) \times \mathrm{f}_{\mathrm{EC}(\alpha)}^{?}(\mathrm{x}) \mathrm{dx},
$$

where $\mathrm{f}_{\mathrm{EC}(\alpha)}^{\text {? }}(\mathrm{x})$ is the risk-neutral probability density function of the annual P\&L, given by:

$$
\mathrm{f}_{\mathrm{EC}(\alpha)}^{?}(\mathrm{x})=\mathrm{Q} \quad \Phi^{-1} \mathrm{f}_{\mathrm{EC}(\alpha)}(\mathrm{x})+\lambda,
$$

with $Q$, the Student-t distribution with degree of freedom $\mathrm{k}$ and $\lambda$ the Sharpe ratio.

\section{Data}

The computation of the FF2F model is only done for the European quoted insurance companies from 2000 to 2007. To make the results comparable, all the returns are converted in US dollars. The data relative to the individual returns come from Bloomberg. The risk premia relative to the financial distress come from the Fama-French database whereas the business mix were obtained from the Eurothesys database. The market index is country specific. The risk-free rate is the Libor 1-Month expressed in US dollars. Table 1 provides the different considered states and the number of companies per state and per year.

The length of the sample is quite stable over years. In addition to that, it appears clearly that the Great Britain, Germany and Italia are the more represented states in our sample. Even if the French market is a major European 
insurance market, just some companies are quoted, reflecting the fact that a lot of insurance activities are realized by mutual insurance companies. In this case, the cost of capital rate is not computed.

In order to discuss results get from FF2F and frictional costs models, we use also data provided by the insurance linked securities market. This market corresponds to a partial secondary market of insurance risks. We do not consider the insurance linked securities covering mortality risk, embedded value or industrial risk.

Figure (1) provides the evolution of a spread index tracking the spread behaviour between August 1st, 2006 and March 31st, 2008 for some risk levels: bonds having an expected loss between $0.5 \%$ and $1 \%$ and bonds having an expected loss between 1\% and 2.5\%. Each index has the value 100 on January 1st, 2004. First of all, it is possible to highlight that the different levels of risk are characterized by different levels of the index. Riskier are the bonds, higher is the index. That reflects the fact that the insurance linked securities having the highest expected loss were characterized by the more increasing trend of their spreads between 2004 and August 2006. Then, between August 2006 and March 2008, all the risks have some similar evolutions, even if the bonds having an expected loss between $1 \%$ and $2.5 \%$ have a more increasing trend than the riskier one, at the end of the considered time period. Lastly, as it is explained in Gatumel and Guégan (2008), the underlying risk, both real and perceived, allows to explain the evolution of the indices. For example, we can easely highlight the seasonality of the US hurricanes. Indeed, for each risk level, the spreads are increasing from March to the end of August.

\section{Basic results}

\subsection{FF2F model}

The estimation is done in three steps. Firstly, the individual beta of each insurance company is computed. Then, the beta of each line of business is estimated following the business mix of the insurance companies. Lastly, the cost of capital rate is calculated by using long run historical returns as presented in Chief Risk Officer Forum (2008):

- $\quad$ Excess market return : 7.81\%,

- $\quad$ BV-MV (Value) risk premium : 4.92\%.

The results for non-life and life segments are presented in table 2 and 3 . The cost of capital is much higher for life insurance than for non-life. The $\beta$ market risk is much lower for the non-life insurance than for the life insurance reflecting the fact that life insurance is more exposed to the market risk. Both are more exposed to the market risk than to the "value" risk. The market risk $\beta$ is in a range $0.772-1.111$ for life insurance whereas the value $\beta$ is in 
a range 0.146-0.336. The results are quite similar for life insurance: 1.1462.078 against $0.179-0.403$. Thus, the total risk premium is mainly driven by the market risk premium. For life insurance the market risk premium explains at least $85 \%$ of the total risk premium. For the non-life insurance, the ratio is around $80 \%$.

The results are comparable to the one get by Chief Risk Officer Forum (2008). However, they seem to be globaly lower and more stable, in particular for the non-life insurance. Indeed, our total risk premium is in a range $7.7 \%$ 9.8\% whereas Chief Risk Officer Forum (2008) gets a total risk premium between $5.66 \%$ and $10.86 \%$ for the same time interval. These differences may be explained by some differences in the initial company sample and the use of country-specific indices instead of an global European index as in Chief Risk Officer Forum (2008).

\subsection{Frictional cost approach}

Compared to the results get with the FF2F approach, modelling the frictional costs allow to obtain a lower cost-of-capital rate. Figure (2) shows that the risk premium for insurance business is in a range $2 \%-4 \%$, whatever the type of risk - life or non-life business - but depending on the return period. $3 \%$ corresponds to the $0.01 \%$ return period, focused by Solvency II.

\section{Discussion on the models}

\subsection{Underlying capital issue}

Firstly, as presented in Chief Risk Officer Forum (2008), the cost of capital for the market value margin is not equivalent to the total return required by shareholders. Not all the realized equity risk premium may be related to the pure risk premium due to risky liabilities. Part of the premium is for example due to the asset liability management policy or to the future profit expectations. Thus the cost of capital rate computed from the Full-Information Industry Beta methodology is not able to valuate the market value margin of the in-force business only.

Second, following Equation (1.1), the market value margin is calculated as the present value of the cost of holding the solvency capital requirement during the whole run-off period of the in-force portfolio. Thus, according to us in such a framework, the cost-of-capital rate has to be consistent with the underlying capital. At this stage, the Fama-French methodology is characterized by two main drawbacks: first, premia do not reflect the allocated risk capital and second, the return appears to be constant whatever the return period. 
A major issue in the Full-Information Beta methodology is the determination of the components of the betas of both the market and value risk premia. Indeed, these components are computed using the business mix of each insurance company. Nevertheless the business mix does not reflect exactly the part of each segment in the total allocated capital risk of the company. The annual financial report of the Allianz Group illustrates this point:

- $\quad$ in 2008, the gross premiums written were closed to e44 billions for the property-casualty insurance operations against e 47 billions for life/- health operations.

- $\quad$ nevertheless, the risk report shows that the allocated internal risk cap- ital is mainly driven by property-casualty at the group diversified level: the diversified risk capital (actuarial risk, credit risk, market risk and operational risk) is about e 16 billions for $\mathrm{P} \& \mathrm{C}$ activities whereas is it only of e 8 billions for life/health activities.

Thus, following the basic approach of the FIIB methodology, the weights $\omega_{\text {if }}$ would be respectively $47 \%$ and $53 \%$ for non-life and life insurance whereas it would be $66 \%$ and $33 \%$ following an approach based on the relevant exposed capital. This would cause some major differences in the computation of the betas and of the risk premia per lines of business. Unfortunately, such information is not available for all the companies of our sample. Thus, we are not able to assess the consequences of using the allocated risk capital instead of the business mix in the computation of the FIIB methodology. In particular, companies are not encourage to transfer the risk : 6\% may be consider as a low risk premium compared to the reinsurance premium which would allow to reduce the SCR at the $99 \%$ quantile.

Another limitation of the Full-Information Industry Beta methodology is that it does not allow the cost of capital rate be varying with the confidence interval at which capital requirements are calculated. Even if Solvency II consider only one cost of capital rate, such an approach is irrelevant in order to optimize business of an insurance company.

\subsection{Risk premium issue}

In order to calibrate the betas and the risk premia we use, after Chief Risk Officer Forum (2008) and Cummins and Phillips (2005), a long run historical returns computed in the total market, with companies reflecting all the economy sectors. Nevertheless, we may be interesting to know if such a risk premium is relevant for insurance companies.

Figure (3) provides the return on equity (ROE) of all US industries and US P\&C Insurers from 1987 and 2008. It appears clearly that the ROE of US insurers is always, excepted in 1987, below the global ROE of all the industries. The average return on equity of all US industries is equal to $13.2 \%$ whereas it 
is equal to $8.7 \%$ for the $\mathrm{P} \& \mathrm{C}$ insurers. The gap may be so high that the ROE of US insurers is negative whereas the global economy remains profitable, like in 2001. Moreover, the ROE of US insurers is more volatile than the ROE of all the industries, reflecting the evolutions of the economy as a whole but also more particular issues. For example, all major troughes of the curve may be related to catastrophic events, like Andrew (in 1992), the Northridge earthquake (in 1994) or the WTC attack (in 2001). On the contrary the good results of 1997 are due to the lowest catastrophic events in 15 years.

That means that the long run historical return calibrated in the total market does not reflect the return required by investors who purchase insurance assets. It may reflect a total return required on the insurance companies, considering that they represent a basket of diversified risks. But, it does not take into account the pure cost of capital required by life or non-life risks. Two main interpretations are possible. Either the true required return for pure insurance assets is lower than the long run historical return calibrated in the total market in order to take into account the fact that the ROE for insurance industry is lower than the ROE for all industries. Or, the required return for insurance assets is higher in order to remunerate investors who purchase assets characterized by a higher volatility.

According to us, the risk premium for the insurance companies has to be lower than the risk premium of the other sectors. Firstly, the core insurance business is quite orthogonal to the rest of the economy. Indeed, catastrophe losses, legal changes, or car damages are not directly linked to the state of the economy. Thus, insurance companies introduces a diversification effect in the investor portfolio which has to be remunerated by a lower risk premium. In addition to that, insurance activity is characterized by a time difference between the premium collecting and the losses payment. Thus, premia provide liquidity to the insurance companies which allow them to develop highly profitable asset management actitivity. Accordingly, the cost of capital rate applied on pure insurance business must neither to include an additional return for asset management activity, and neither an additional return for the asset risk, because we are focusing on the pure insurance business.

The basic computation has been done assuming that the long-run excess market premium is equal to $7.81 \%$. Table 4 provides some results due to a change in the $\mathrm{P} \& \mathrm{C}$ risk premium for the year 2008. Considering other long-run premium may divide by two the $\mathrm{P} \& \mathrm{C}$ total premium.

\subsection{Agency costs issue}

The agency costs are due to the misalignment of the interests of senior management and shareholders. Chief Risk Officer Forum (2008) does not modelled them because it assumes that they are more related to the franchise value than to non-hedgeable risk on the in-force business. In addition to that, it believes that the supervisor scrutiny help management to meet its obligations, 
in particular in situation of financial distress. Even if Chief Risk Officer Forum (2008) highlights the fact that the misalignment should be reflected in a higher cost of capital rate, it decided that it was inappropriate to model them. This point of view is really difficult to interpret.

First of all, the uncertainty is a major component of the cost of capital rate. That may be highlighted by the insurance linked securities market (see for example Gatumel and Guégan (2008)). Before Katrina, the spreads in the market are almost stable, slightly decreasing. The hurricane causes a major change in the market. The spreads blow up immediately after the catastrophe and they are characterized by an increasing trend during one year. We may explain this behaviour as follows. Before Katrina, investors were interested by the trade of this type of risk and quite confident in the issued risk. But Katrina, and the first default of a bond, changed the risk perception. And even if the traded risk was similar, investors required a higher return in order to buy it. We may easily assume that it would be quite similar for an insurance company. As long as it is not characterized by financial distress, investors would require a return driven by the financial perspectives. But an adverse signal would not only modify them but also wouldn't put them at ease relatively to the future. Thus, investors would require a higher return which is not captured by the methodology of Chief Risk Officer Forum (2008). And even regulatory oversight is likely to increase, it would affect future business and future profit opportunities of the investors. Indeed, we may easily expect that the regulatory oversight would be linked to a very prudential strategy and thus to a limited return on equity. That phenomen would reinforce the increase trend of the cost of capital at which the company would find money. That is for example clearly the case with the companies which have been restructurated following the 2008 financial crisis. Their share prices is very low reflecting the fact that the investors require a high risk premium in order to purchase them.

The argument of Chief Risk Officer Forum (2008) is that the agency costs are more or less taken into account through parameters $\lambda$ and $\mathrm{k}$ of the riskneutral distribution. We agree with that. However, it appears that the parameters chosen are irrelevant. Indeed, as explained in Wang (2004) the Student-t distribution is used in order to take into account the uncertainty in the parameter estimation. The uncertainty is due to the limited available data, to the uncertainty in the estimation of catastrophe losses and to the fear of the investors. Consistently, we may expect a decreacreasing link between the market price of risk and the degrees of freedom of the Student-t distribution. Higher would be k, more Gaussian would be the Student-t distribution, reflecting a lower uncertainty and thus, lower would be the risk premium required by the investors. On the contrary, with a high uncertainty, k would be small and the market price of risk would be high. That does not appear with the parameters chosen by Chief Risk Officer Forum (2008). The parameters $(\lambda, \mathrm{k})$ are respectively $(0.75,0.6)$ and $(0.45,5)$. With the results presented in Gatumel and Guégan (2008) we get some different results provided by Figure 
(4).

It appears that the cost of capital rate is an increasing fonction of the parameters $\lambda$. Higher is the market price of risk in the insurance linked securities market, higher is the cost of capital rate, whatever the return period. Our results differ slightly from the results of Chief Risk Officer Forum (2008). We get a range $2.4 \%-4 \%$, mainly due to the fact that our computation does not provide a $\lambda$ parameter as much high as 0.75 .

\subsection{Technical issue}

The first technical issue of the frictional cost approach is the assumption of a P\&L distributed following a Gaussian distribution. We understand that it is a traditional and practical assumption. Nevertheless, it seems to be not appropriate. We consider that if we want to capture the behaviour of the solvency capital requirement, we have to capture the real beaviour of the tails of the P\&L distribution. A Gaussian distribution does not allow that because it does not allow to capture the fact that insurance industry is characterized by the fact some adverse events occur more often than expected. Thus, the tails of the P\&L distribution would by ticker than those of the Gaussian distribution.

With a non-Gaussian distribution, the double-taxation cost component of the frictional cost approach may be discussed. Indeed, the cost of capital rate is a return applied on the solvency capital requirement in order to capture the market value margin. In others words, it is a return applied on a necessary capital to support insurance obligations over their life time. By definition, this capital would be used in order to cover some adverse events like a major deviation of the past reserves or some underwritting issues. Mispricing or unexpected major catastrophic events may explain such a result. Thus, the solvency capital requirement aims at covering a negative result, that means a result not directly concerned by tax issues. With a Gaussian P\&L assumption, a tax carry forward period seems to be relevant because tax on past negative result may be used in order to reduce tax on future positive result. But, with a P\&L distribution having tick tails, negative results of one year cannot be used to reduce future tax issues. We may illustrate that point through AIG bankruptcy. The negative results of the insurer does not create deferred tax because of the bankruptcy of the group.

\subsection{Premium per risk issue}

Compared to the Fama-French Two Factors model, the frictional cost approach is not based on market data and depends on a lot of assumptions. For example, the components of the frictional costs, the way to take into account the agency costs or the way to model the P\&L are crucial in the final cost-of-capital rate. On the contrary, it allows to determine a pure insurance cost of capital rate. 
It possible to reconcile both approaches by using data of the insurance linked securities market. Indeed, because pure insurance risk are regularly traded in this market, it offers the way to understand how the investors valuate the insurance risks. Moreover, some models have been developped in order to capture the market price of risk in this market (see for example Gatumel and Guégan (2008)).

For example the Fermat Capital Management model considers that the rate on line of the insurance linked security i has the following form:

$$
Y_{i}=X_{i}+\beta \times M P R,
$$

where: $Y_{i}$ is the rate on line or, more commonly, the spread or, the cost of capital rate,

$\mathrm{X}_{\mathrm{i}}$ is the Expected Loss,

$\beta=\frac{1}{\bar{m}_{\mathrm{i}}}$, with $\mathrm{m}_{\mathrm{i}}$ the weight of the risk covered by the issue $\mathrm{i}$,

MPR $=\lambda \times{ }^{\mathbf{P}} \overline{\mathrm{X}_{\mathrm{i}} \times\left(1-\mathrm{X}_{\mathrm{i}}\right) \text {, }}$

$\lambda$ is the Sharpe Ratio, according to the Fermat model.

In other words, the Fermat model may be written as:

$$
Y_{i}=X_{i}+\lambda \times \frac{\mathbf{P}_{\overline{X_{i} \times}\left(1-X_{i}\right)}}{\overline{m_{i}}} .
$$

Following the fact that the bonds are regularly traded, $\lambda$ evolves over time, reflecting the fair value of the risk in the insurance linked securities market:

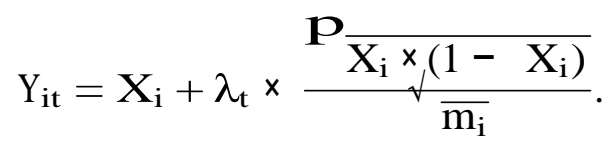

By using the data relative to the secondary market at date $t$, it is possible to capture the Sharpe Ratio at each date. Moreover, by considering some classes of risk, it is possible to determine a Sharpe Ratio and a cost of capital rate for different level of risk.

Figures (5) and (6) provide the evolution of the estimated Sharpe Ratio and of the Cost of Capital rate between August 1st, 2006 and March 31st, 2008 for three levels of risk. We consider the bonds having an expected loss under $0.5 \%$, between $0.5 \%$ and $1 \%$, and between $1 \%$ and $2.5 \%$.

As it is the case for the evolution of the insurance linked securities index, the Sharpe Ratio depends on the risk level. The lower the risk, the higher is the required return per unit of risk. That reflects the fact that the investors are relatively more risk averse for the bonds having a lower return period. We may explain that by assuming that this type of bonds are characterized by a big uncertainty, even if it is not captured by the expected loss. Thus the investors require a relative higher return in order to accept the risk. In addition to that, the Sharpe Ratio is globally decreasing between August 2006 
and March 2008 capturing the decreasing trend of the insurance linked securities spread index over the same period. No major catastrohic event, the independance between the "classical" financial markets and the catastrophe bond market, the increasing demand for this type of risks explain this phenomenon. The peak of the Sharpe Ratio for the bonds having an expected loss above $2 \%$ during the summer 2007 may be explained both by the season and by the financial crisis. Obviously, at the end of the hurricane season and with the independance of the catastrophe bond sphere, the Sharpe Ratio is decreasing.

A major element between on the one hand the cost of capital rate and on the other hand the expected loss and the market price of risk is the diversification factor $m$. This factor aims at capturing the diversification effect introduced by the risk covered by the issue $\mathrm{i}$ in the portfolio. Higher will be the diversification effect, lower will be the ratio of the market price of risk by the diversification effect and thus lower will be the cost of capital rate. In the model, $m$ depends on the global exposure which is underlying of the risk traded. For example, if the global exposure - at the market level - on the US hurricanes is $\$ 120$ billion for a centenary event, if the exposure for the same return period but for the Californian earthquake is $\$ 90$ billion and if it is $\% 70$ billion for the European windstorm, $\mathrm{m}$ is equal to 1 for bonds covering the US hurricanes, 2 for the Californian earthquake and 3 for the European windstorm. In other words, the exotic risks, like the Australian windstorm, are characterized by a lower risk premium because they allow to reduce the global risk of the portfolio. For a given expected loss, the cost of capital rate will be a decreasing function of the diversification factor. Figure 6 points out this phenomena.

Each curve represents the evolution of the cost of capital rate for a given return period, a given diversification factor and the market price of risk previously estimated. It appears clearly that higher is the expected loss, higher is the cost of capital rate. In addition to that, higher is the diversification factor, lower is the cost of capital rate. Indeed, for a given diversification factor, for example $\mathrm{m}=3$, it appears that the cost of capital is between $4-4.5 \%$, when the expected loss is equal to $0.5 \%$, and $7-8 \%$ for an expected loss equal to $2 \%$. But for a same expected loss, for example $0.5 \%$, it appears that the cost of capital may vary in a range $4-8 \%$, depending on the diversification factor.

To summarize, it appears clearly that the cost of capital rate has to be depending on the considered return period and on the allocated risk capital of the underlying segment. Higher will be the part of a segment in the global risk capital, higher will be the cost of capital applied on the required capital. The segment may interpreted in two ways. For example the segments may be considered as the sources of risk. In the 2007 annual report of Allianz AG, it appears (page 91) that the property-casualty actuarial risks may be divided into the Premium CAT risks (27\%), the Premium non-CAT risks (38\%) and the Reserve risks (37\%). Following the fact that Allianz calculates the allocated risk capital with a Value-at-Risk at $99.97 \%$ as risk measure, the cost of 
capital rate for each segment would be the following: $7-8 \%$ for the Premium non-CAT risks, $6 \%$ for the Reserve risks and $4.5 \%$ for the Premium CAT risks. But, the segments may also be considered as the different lines of business of the company: personal property, commercial property, motor, liability, etc. In this case, there won't be a cost of capital rate by source of risk but a cost of capital rate by line of business $x$ source of risk. It will allow not only to capture the current exposure of each line of business but also the portfolio evolution by considering the different diversification factors used for example both for the Premium risk and for the Reserve risk.

It is very important to point out that, following such an approach, all the insurance companies wouldn't be characterized by the same cost of capital rate. Indeed, the cost of capital rate would depend on the business structure of each company. Moreover, this study is based on the example of the insurance linked securities market, because it is the more transparent exchange market of insurance risks. Thus, the cost of capital rates that we have determinated do not include a high liquidity premium. Because all the insurance portfolios are not traded in this market, the cost of risk applied on the allocated capital risk of the global portfolio of an insurance company should capture this additional risk. Thus, the cost of capital rate have to be higher than what we have previously determinated.

\section{Conclusion}

According to the pricing theory applied to incomplete markets, the cost-ofcapital rate adopted by the supervisory authorities is fair : 6\% is inside a range given either by market data or by modelling assumptions. Thus, with a $6 \%$ cost-of-capital rate, it is possible to get a fair value of insurance liabilities. In addition to that, $6 \%$ is quite low compared to the characteristics of the price interval : each price between $2.5 \%$ and $15 \%$ may be considered as fair!

Having in mind that the cost-of-capital rate used to compute the market value of insurance iabilities has to be paid to the investors, we consider that a costof-capital rate equals to $6 \%$ is conservative. It appears to be consistent with the return-on-equity get from traditional portfolio strategy. A higher cost-ofcapital rate would be the source of potentially riskier strategies in order to win a higher return-on-equity. The portfolio allocation would be riskier inducing solvability issues both for insured and shareholders. 


\section{References}

Black, F. and Scholes, M. (1973). The Pricing of Options and Corporate Liabilities. Journal of Political Economy, 81(3):637-654.

Chief Risk Officer Forum (2008). Market Value of Liabilities for Insurance Firms: Foundation Elements for Solvency II. Technical report.

Cummins, J. and Phillips, R. (2005). Estimating the Cost of Equity Capital for Property-Liability Insurers. Journal of Risk \& Insurance, 72:441-478.

Ehrhardt, M. and Weiss, M. (1992). A Full-Information Approach for Estimating Divisional Betas. Financial Management, 20:60-69.

Embrechts, P. (2000). Actuarial Versus Financial Pricing of Insurance. The Journal of Risk Finance, 1:17-26.

European Commission (2007). Proposal for a Directive of the European Parliament and of the Council on the taking-up and pursuit of the business of Insurance and Reinsurance, Solvency II. Technical report, European Commission.

European Insurance and Reinsurance Federation (2008). Cost of Capital Methodology. Technical report.

Gatumel, M. and Guégan, D. (2008). Towards an Understanding Approach of the Insurance Linked Securities Market. Working Paper 2008.06, Centre d'Economie de la Sorbonne, University of Paris 1.

Hancock, J., Huber, P., and Koch, P. (2001). The Economics of Insurance: How insurers create value for shareholders. Technical report, Swiss Re.

Kaplan, P. and Peterson, J. (1998). Full-Information Industry Betas. Financial Management, 27:85-93.

Merton, R. (1973). Theory of Rational Option Pricing. Bell Journal of Economics, 4(1):141-183.

Mø ller, T. (2002). On Valuation and Risk Management at the Interface of Insurance and Finance. British Actuarial Journal, 8(4):187-827.

Vaughn, T. (1999). Property/Liability Insurance Risk Management and Securitization. Technical report, Casualty Actuarial Society Discussion Paper Programm.

Wang, S. (2004). Cat. Bond Pricing Using Probability Transforms. Geneva Papers: Etudes et Dossiers, Special Issue on "Insurance and the State of the art in Cat. Bond Pricing, 278:19-29. 


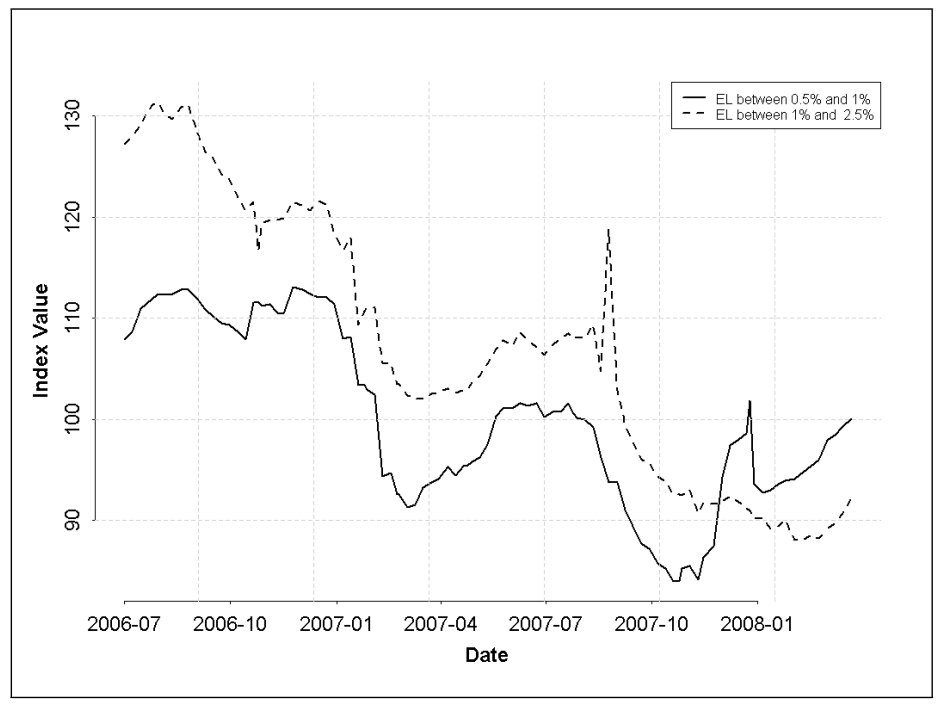

Figure 1: Evolution of the Cat. Bond Spread Index since August 1st, 2006.

\begin{tabular}{cccccccccc}
\hline \hline & 2000 & 2001 & 2002 & 2003 & 2004 & 2005 & 2006 & 2007 & Market Index \\
\hline BE & 3 & 3 & 3 & 2 & 2 & 2 & 2 & 2 & BEL20 Index \\
CH & 6 & 6 & 7 & 7 & 7 & 7 & 7 & 7 & SMI Index \\
DE & 16 & 15 & 15 & 14 & 14 & 16 & 14 & 14 & HDAX INDEX \\
ES & 1 & 1 & 1 & 1 & 1 & 1 & 1 & 1 & MADX Index \\
FI & 2 & 2 & 2 & 2 & 2 & 2 & 2 & 1 & HEXP Index \\
FR & 5 & 4 & 4 & 4 & 3 & 4 & 4 & 5 & SBF250 Index \\
GB & 15 & 15 & 18 & 17 & 19 & 19 & 18 & 17 & NMX Index \\
IE & 1 & 1 & 2 & 2 & 2 & 2 & 2 & 2 & ISEQ Index \\
IT & 12 & 12 & 9 & 9 & 10 & 11 & 11 & 10 & SPMIB index \\
NL & 4 & 3 & 3 & 3 & 3 & 2 & 2 & 2 & AEX Index \\
NO & 1 & 1 & 1 & 1 & 1 & 1 & 1 & 1 & OSEAX Index \\
SE & 3 & 4 & 4 & 5 & 5 & 5 & 5 & 4 & SAX Index \\
\hline Europe & 69 & 67 & 69 & 67 & 69 & 72 & 69 & 66 & \\
\hline
\end{tabular}

Table 1: Number of observations by country and by year - Relevant indices. 


\begin{tabular}{cccccc}
\hline \hline Year & $\beta$ Market.Risk & $\beta$ Value.Risk & Risk Premium Market & Risk Premium Value & Total Premium \\
\hline 2000 & 0.772 & 0.293 & 6.030 & 1.670 & 7.700 \\
2001 & 0.872 & 0.277 & 6.809 & 1.576 & 8.385 \\
2002 & 0.907 & 0.310 & 7.083 & 1.766 & 8.848 \\
2003 & 0.997 & 0.336 & 7.784 & 1.915 & 9.699 \\
2004 & 0.959 & 0.328 & 7.489 & 1.867 & 9.356 \\
2005 & 1.033 & 0.231 & 8.064 & 1.320 & 9.384 \\
2006 & 1.111 & 0.200 & 8.677 & 1.142 & 9.819 \\
2007 & 1.048 & 0.146 & 8.184 & 0.830 & 9.014 \\
\hline
\end{tabular}

Table 2: Cost of capital rate for non-life insurance following the Full-Industry Information Beta methodology.

\begin{tabular}{cccccc}
\hline \hline Year & $\beta$ Market.Risk & $\beta$ Value.Risk & Risk Premium Market & Risk Premium Value & Total Premium \\
\hline 2000 & 1.146 & 0.227 & 8.948 & 1.296 & 10.244 \\
2001 & 1.231 & 0.179 & 9.615 & 1.021 & 10.636 \\
2002 & 1.253 & 0.184 & 9.783 & 1.049 & 10.832 \\
2003 & 1.677 & 0.292 & 13.098 & 1.663 & 14.761 \\
2004 & 1.720 & 0.403 & 13.432 & 2.298 & 15.730 \\
2005 & 1.849 & 0.380 & 14.441 & 2.165 & 16.606 \\
2006 & 2.033 & 0.283 & 15.875 & 1.614 & 17.489 \\
2007 & 2.078 & 0.353 & 16.225 & 2.010 & 18.236 \\
\hline
\end{tabular}

Table 3: Cost of capital rate for life insurance following the Full-Industry Information Beta methodology.

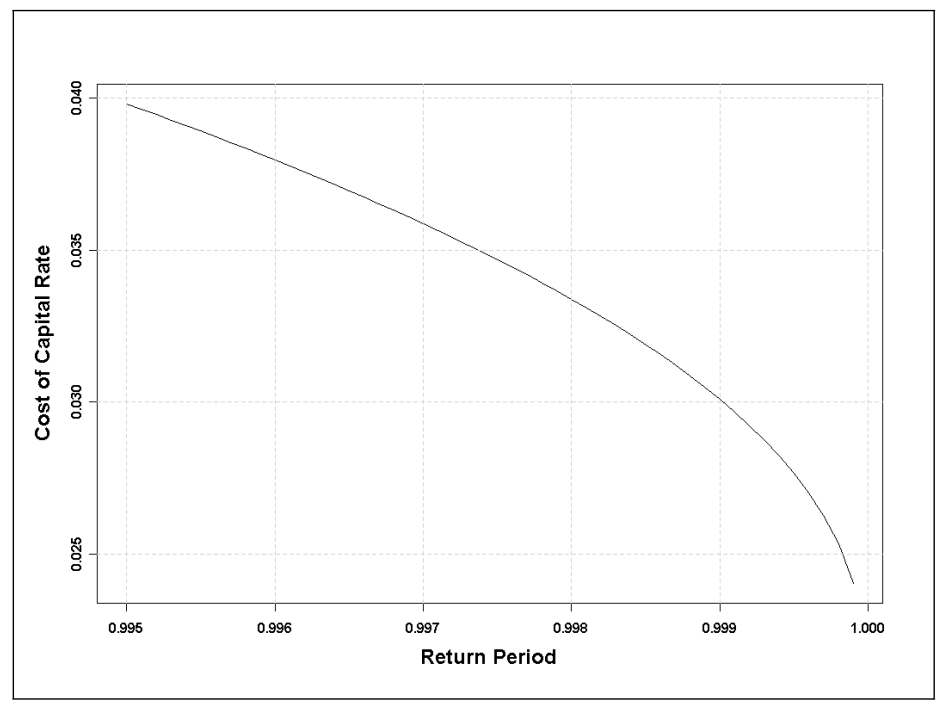

Figure 2: Cost of capital rate per return period following a frictional cost approach. 


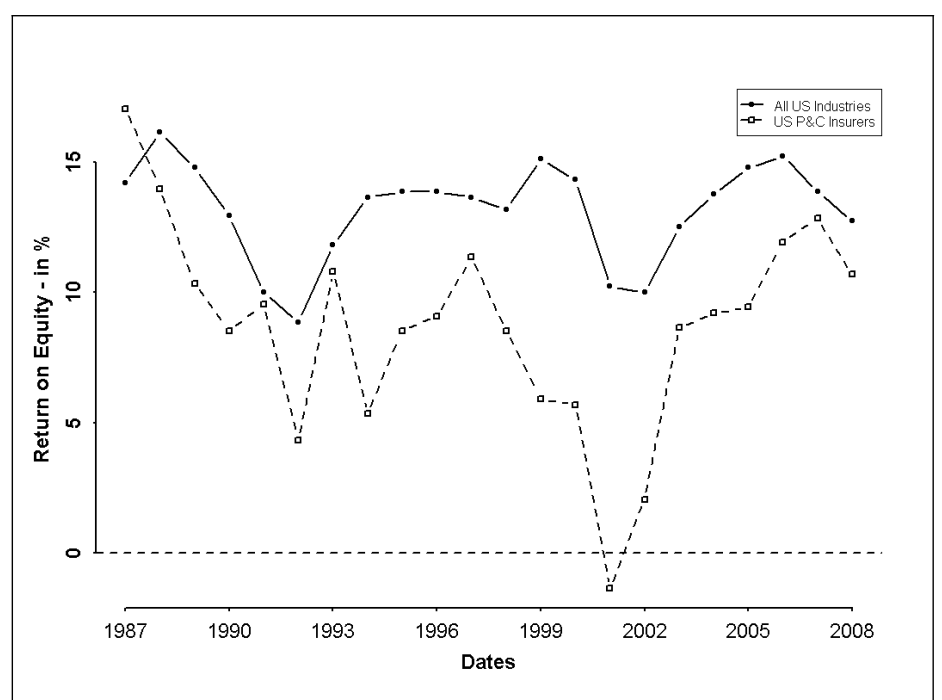

Figure 3: Return on Equity of all US Industries and US P\&C Insurers. source: Insurance Information Institute.

\begin{tabular}{ccc}
\hline \hline Year & MRP & Total Premium \\
\hline 2007 & $7.81 \%$ & 9.01 \\
2007 & $7 \%$ & 8.17 \\
2007 & $6 \%$ & 7.12 \\
2007 & $5 \%$ & 6.07 \\
2007 & $4 \%$ & 5.02 \\
2007 & $3 \%$ & 3.97 \\
\hline
\end{tabular}

Table 4: Consequences of various market risk premia on the total premium for non-fie insurance in 2007

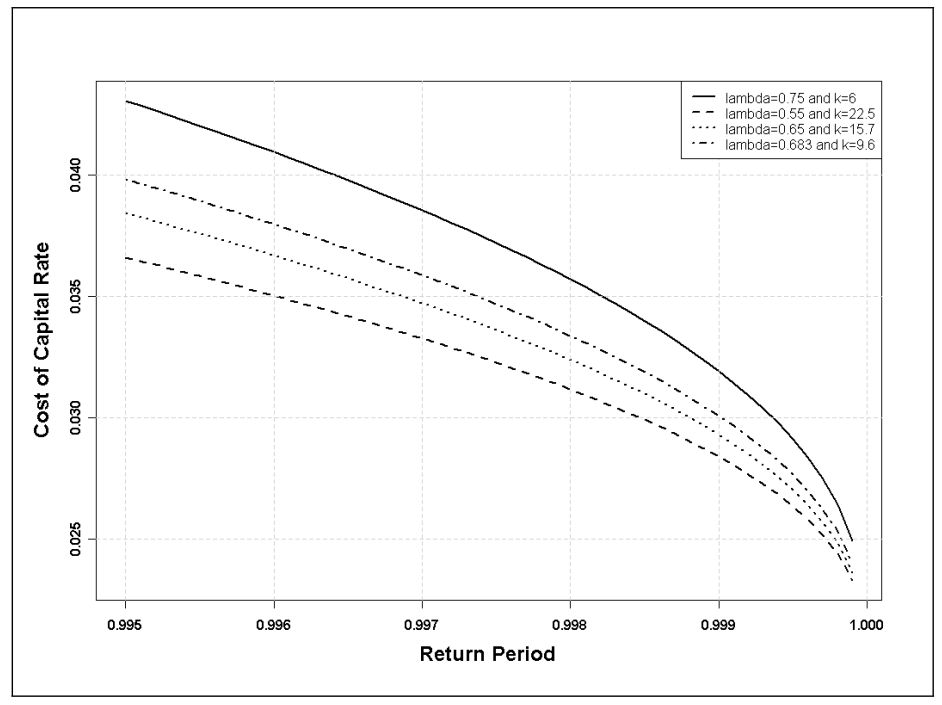

Figure 4: Cost of capital rate per return period following a frictional cost approach and for some $\lambda$ and $\mathrm{k}$. 


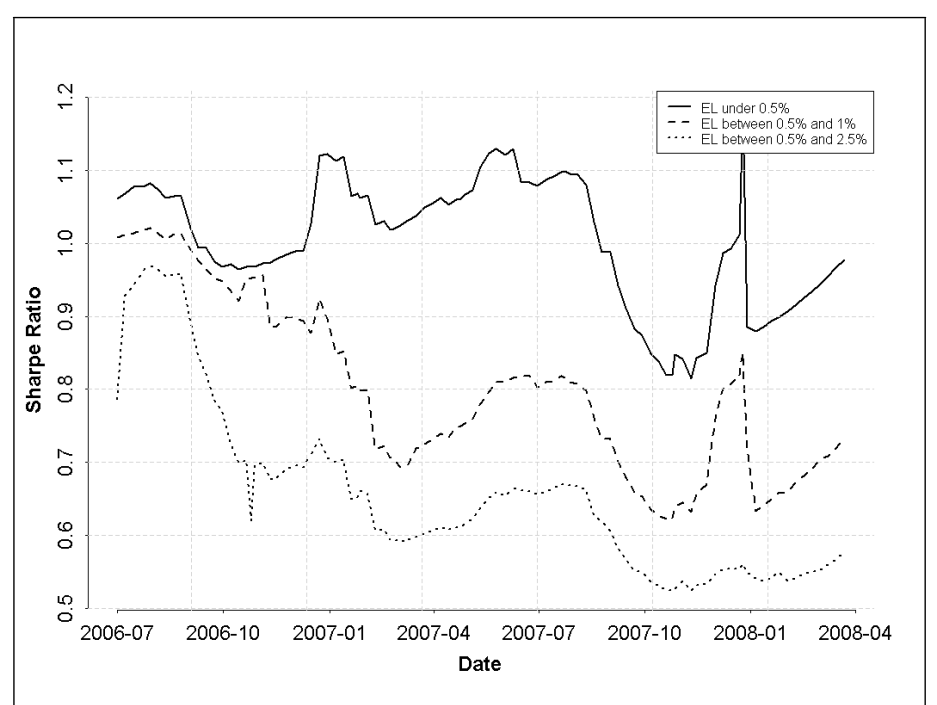

Figure 5: Evolution of the Sharpe Ratio in the ILS market. 


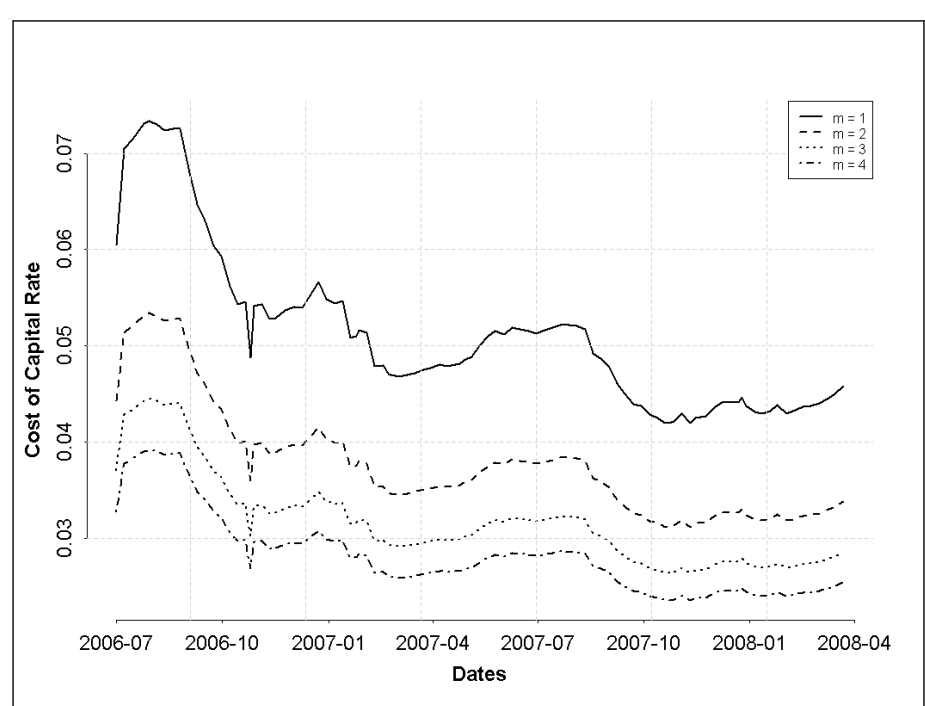

(a) Expected Loss $=0.5 \%$.

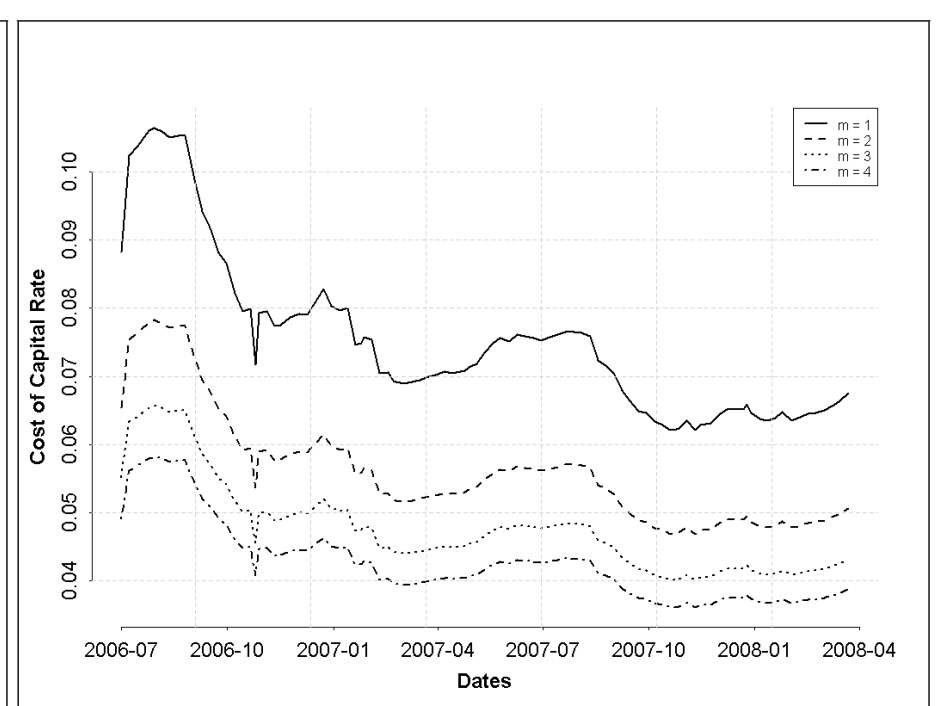

(b) Expected Loss $=1 \%$.

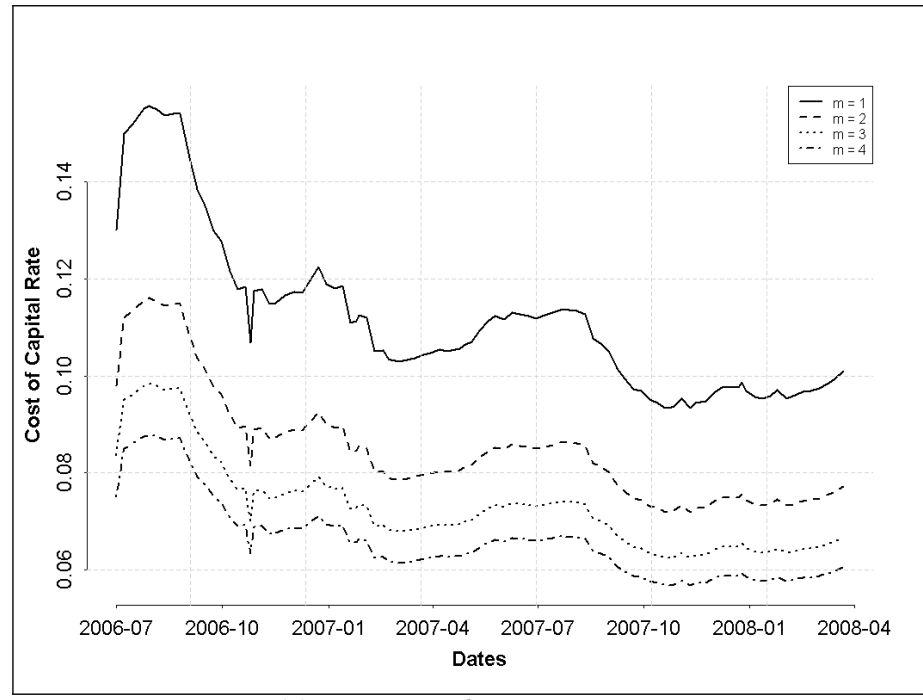

(c) Expected Loss $=2 \%$.

Figure 6: Evolution of the Cost of Capital Rate for different risk levels and diversification factors. 